

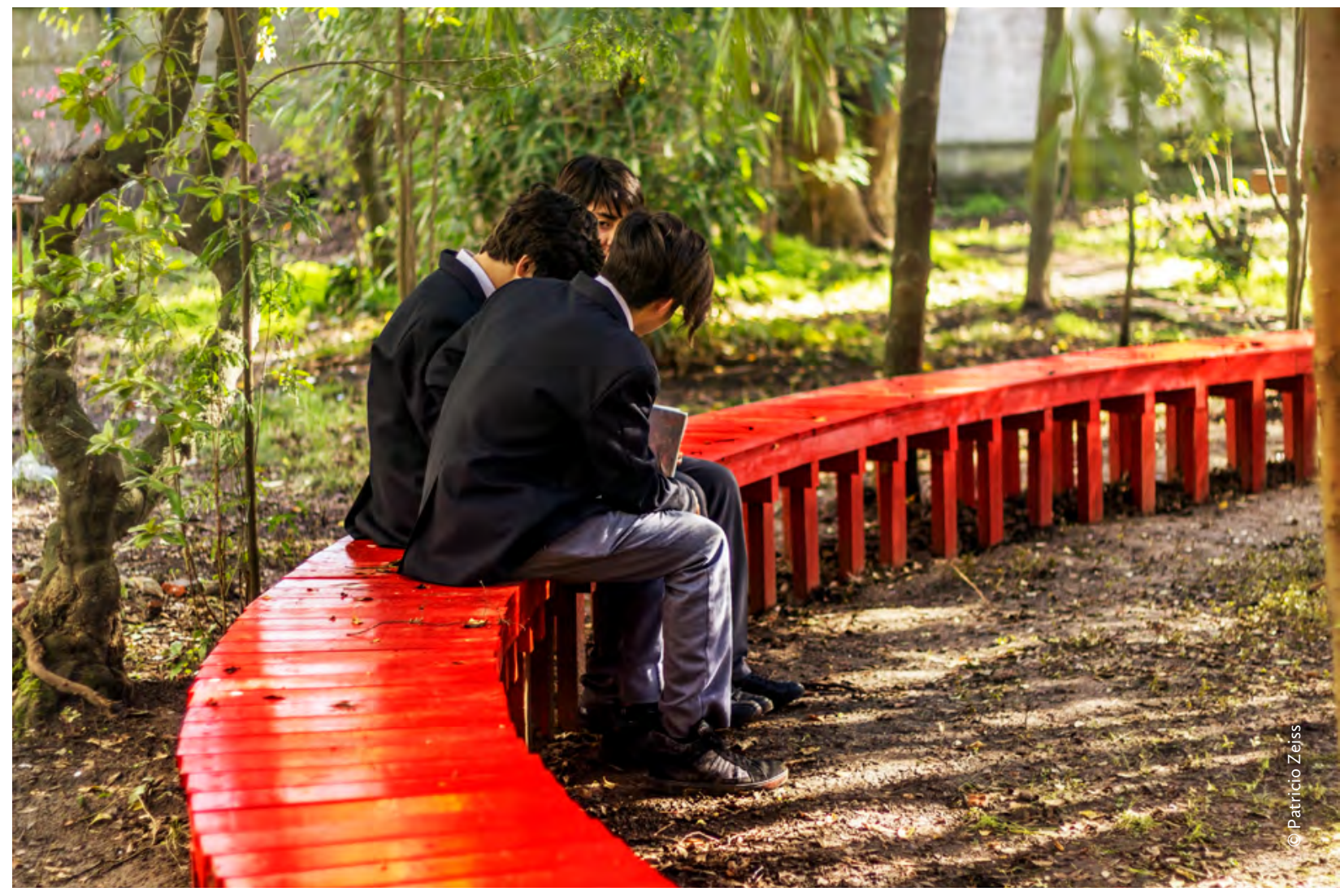

nfinite Bench is an installation developed for the

Alejandro Merino Botanical Garden of the Enrique Molina Garmendia School in Concepción, whose objective is the revaluation and rehabilitation of this space, until now relegated to being the generous front garden of an emblematic building of the city. Because it is visible from the street, it is widely recognized for its scale and for the size of the trees it houses in a dense urban area, appearing like a small forest trapped in the city.

A continuous circular bench with a diameter of 14 $\mathrm{m}$ was proposed for the rehabilitation, which consists of the systematic repetition of 67 wooden modules of trapezoidal base, in a stool-like manner, with an outer side of $61 \mathrm{~cm}$ long and an inner side of $57.5 \mathrm{~cm}$. These were built with $2 \times 3$-inch slats, covering the surface with $1 \times 5$-inch boards. Each module was embedded in the natural terrain, trying to reach a useful height of $50 \mathrm{~cm}$, and were also joined by their edges in order to form the expected circumference. 


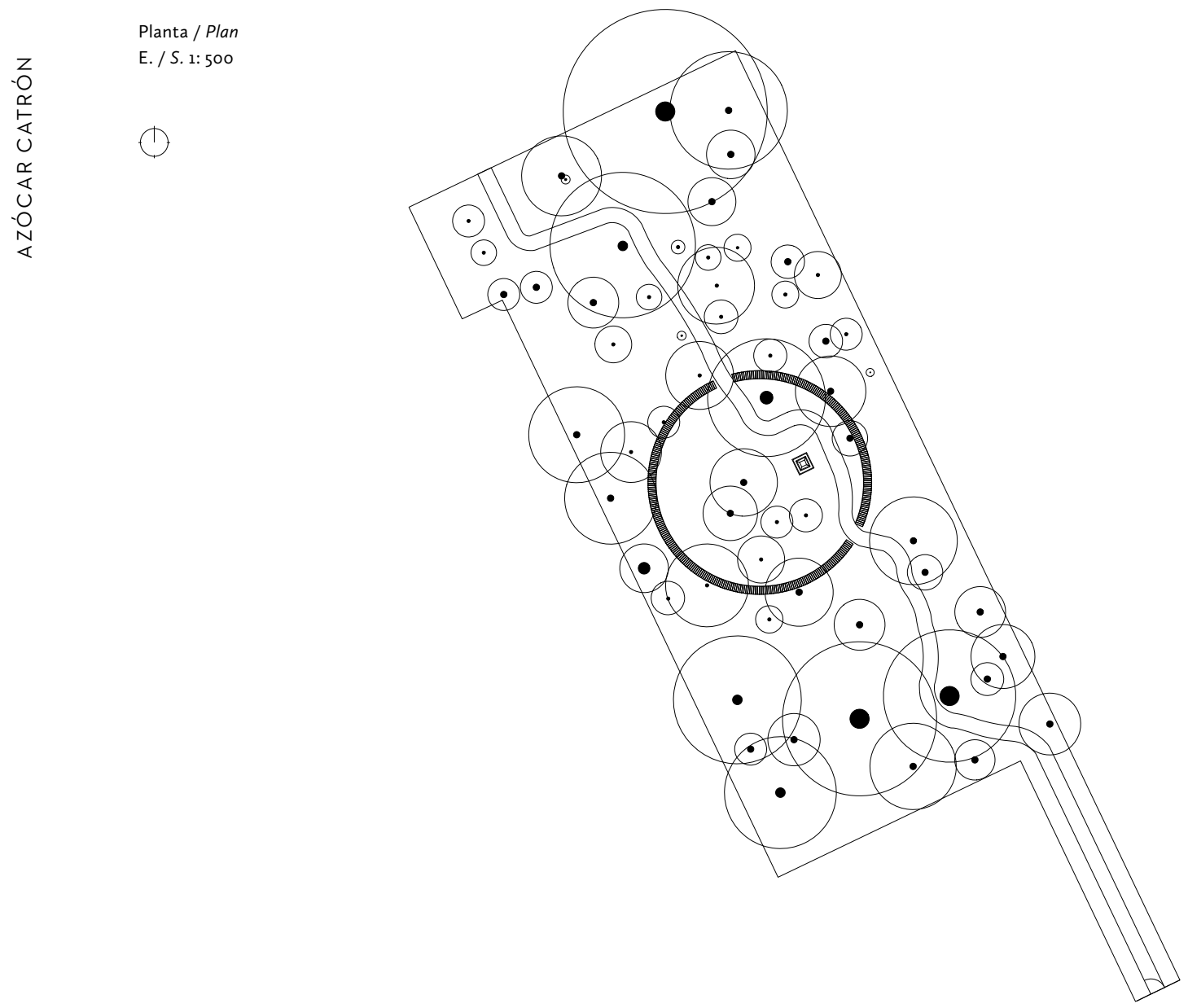

Isométrica banca y posibilidades de uso /

Bench isometric and use possibilities

E. / S. 1: 250
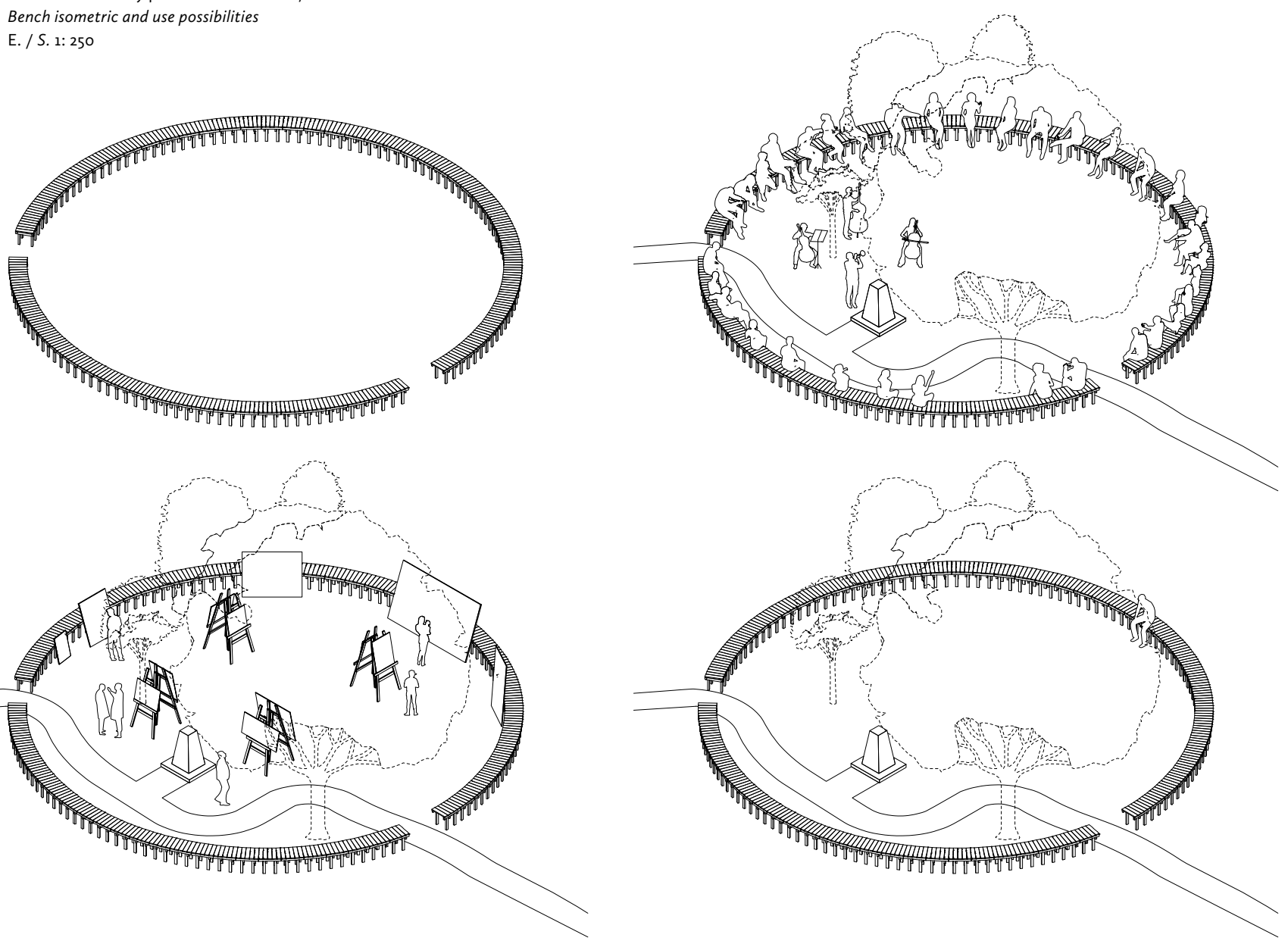

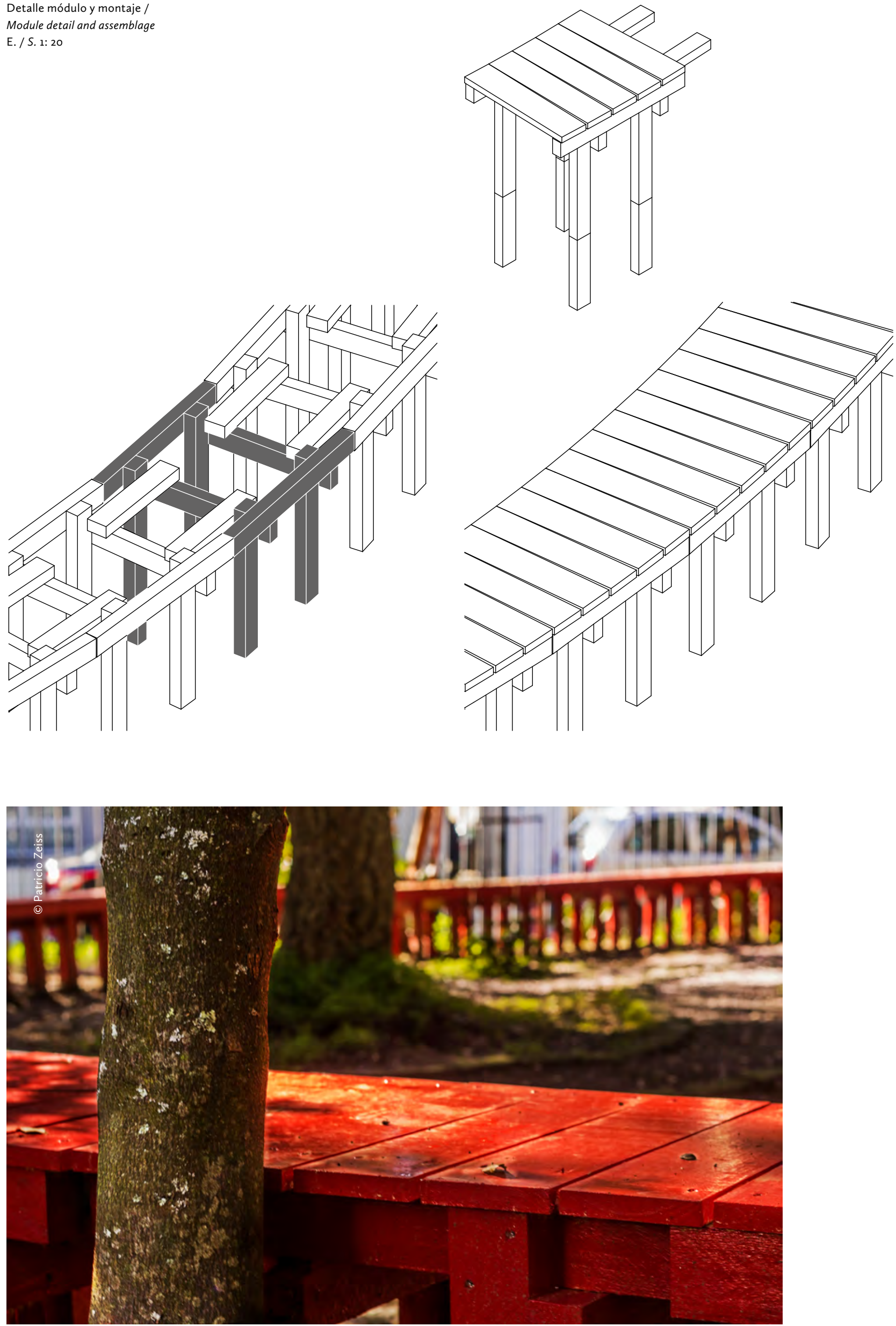


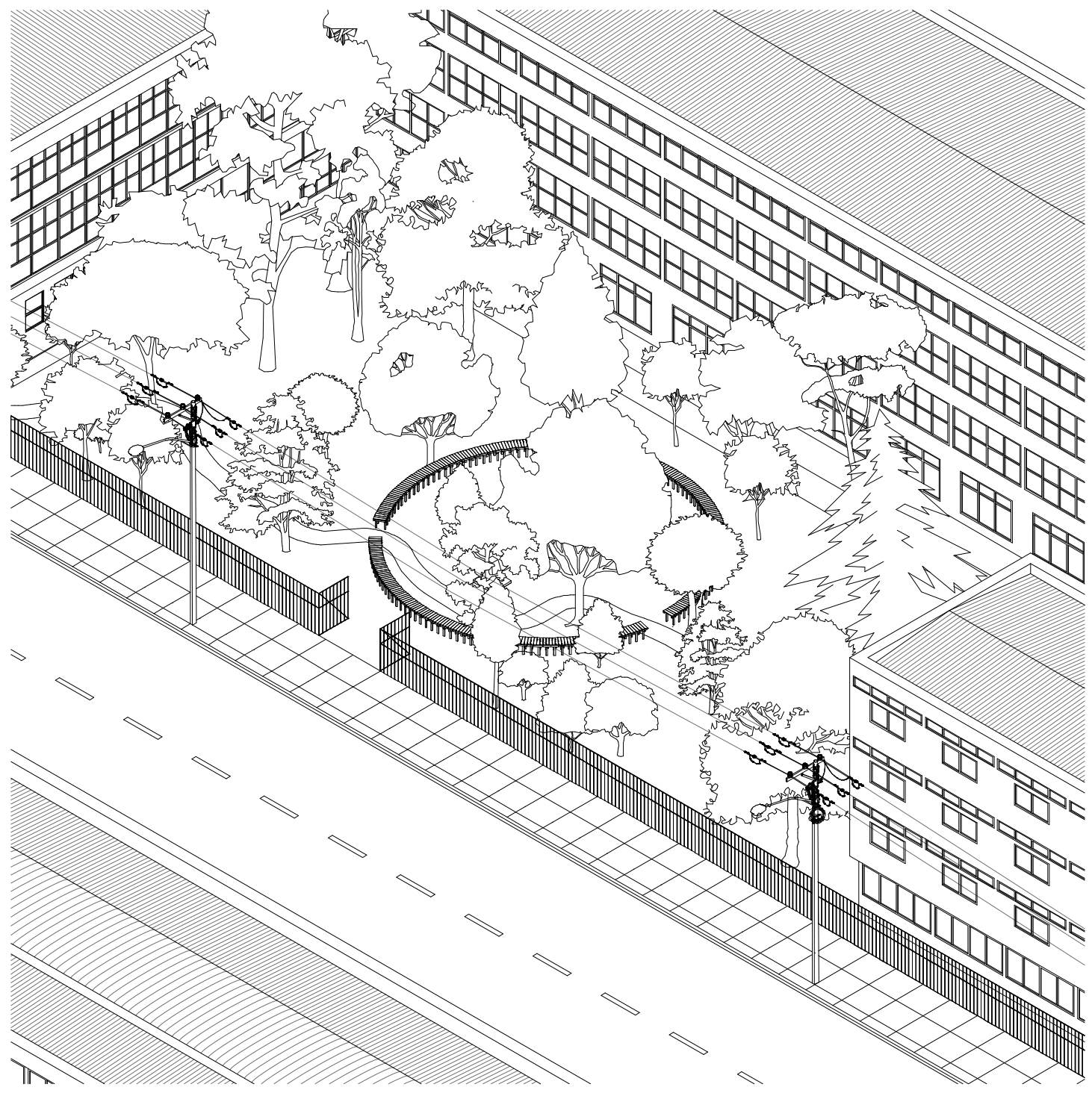

\section{Azócar Catrón}

<info@azocarcatron.cl>

Architecture and urban planning practice and workshop based in Concepción. It was founded by Ricardo Azócar, (architect, Universidad del Bío-Bío, 2016) and Carolina Catrón (architect, Universidad del Bío-Bío, 2016). In 2016, it obtained the Revelation Work award from the Colegio de Arquitectos de Chile and, in 2018, its monograph Catalejo (Editorial Dostercios, 2017), obtained the First Prize of the XIV International Biennial of Architecture of Costa Rica. Its work has been exhibited at the XVI Venice Architecture Biennale "Freespace," at the $x I$ Ibero-American Biennial of Architecture and Urbanism, at the Arc en Rêve Center D'architecture in Bordeaux, among others.

During 2019, its Infinite Bench project obtained the Distinguished Work award at the $\mathrm{x} \times \mathrm{I}$ Biennial of Architecture and Urbanism of Chile, and in 2020 it obtained a Mention in the category of international built work at the vıI International Biennial of Santa Cruz, Bolivia. 


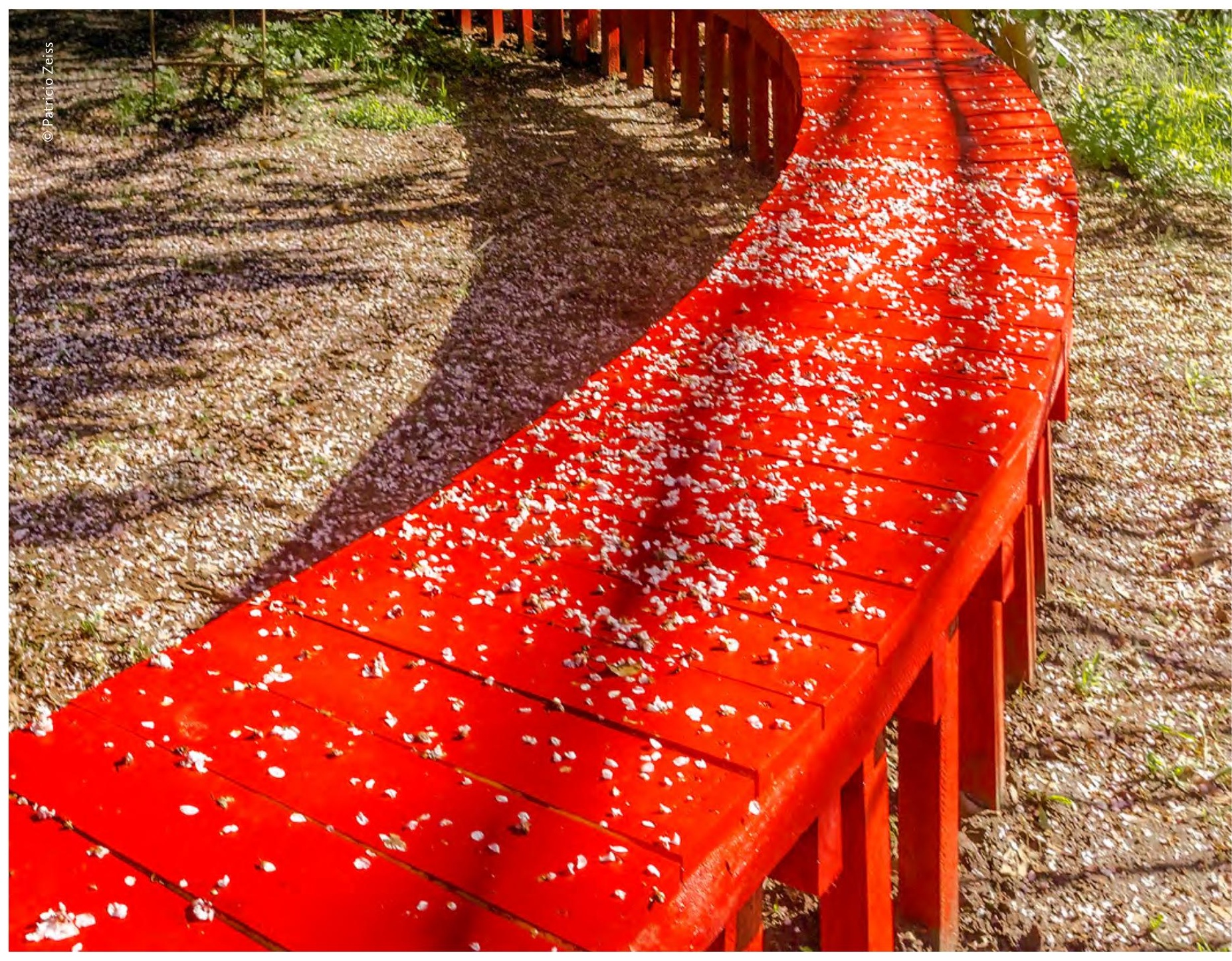

The bench is only interrupted by the existing path, carefully settling among the trees to create a new classroom that blends into the landscape, in which classes, workshops and meetings between the students are expected to be held, reincorporating this place into the daily life of the school, also becoming an iconic object that makes this garden visible within the community of Concepción. ARQ

Arquitectos / Architects: Azócar Catrón

Colaboradores / Contributors: Jorge Lazo, María Florencia Ormeño, Fernanda Pedreros

Ubicación / Location: Aníbal Pinto 31, Concepción, Chile Cliente / Client: Liceo Enrique Molina Garmendia

Construcción / Construction: Eduardo Aburto, Guillermo Medina Materiales / Materials: Madera aserrada impregnada y madera cepillada / Sawn and impregnated wood, brushed wood
Superficie construida / Built area: $20 \mathrm{~m}^{2}$ Superficie del terreno / Site area: $1.034 \mathrm{~m}^{2}$ Año de proyecto / Project year: 2018

Año de construcción / Construction year: 2018 Fotografía / Photography: Patricio Zeiss Visualizaciones / Visualizations: Azócar Catrón Maquetas / Models: Azócar Catrón, Nicolás Becerra 